\title{
THE ROLES OF CORAL TRIANGLE INITIATIVE (CTI) IN REALIZING SUSTAINABLE DEVELOPMENT GOALS WITHIN ASIA PACIFIC WATERS
}

\author{
Anisah Jessica Lee \\ Geoinformatic Unit, Geography Section, School of Humanities, Universiti Sains Malaysia, Penang, Malaysia \\ anisah@usm.my
}

Received: 2 December 2020; Accepted :13 December 2020; Published :31 December 2020

\begin{abstract}
What we do on land will affect the coastal and marine environment and what happens to these environments will affect us in return. Addressing land-based pollution is vital as the terrestrial is connected to the freshwater, the coastal and the marine system. We need to recognize that no one else is responsible for our lives and wellbeing but us. Biodiversity, defined by its genetic, species and ecosystem diversities, need to be conserved for the present and future. Genetic diversity is important for adaptations, species diversity sustains ecosystem equilibriums, and the robust performance of diverse ecosystems is crucial for the mix of life's essentials. Its value extends far beyond fisheries providing natural products and services which life on earth depends on. These resources provide essential economic, environmental, aesthetic, and cultural benefits to humanity. Damage to the reefs due to multitude long term threats, and with the increasing pressure of human population and accelerated demands for food, products, services, and space from these environments, the health of marine biodiversity is becoming huge environmental issue. Globally, we are now left with a daunting prospect of undoing what we have done. Since the ocean and its biodiversity provide livelihoods and a place to live, they are the major contributors to the global economy and fundamental to global wellbeing; through direct and economic activities, provisions of environmental services, and as home to the majority of the world's population. The key issues affecting ocean and biodiversity sustainability have long been ascertained - unsustainable fishing, climate change and ocean acidification, pollution and waste, loss of habitats and biodiversity, and invasive species. Located at the heart of global biodiversity hotspot, the Coral Triangle is a shared marine resource heritage which is a fundamental link between our society, economy, and space. It contributes to the model of sustainability where community's wellbeing and livelihood depend on. A clear understanding of the role of CTI and how it fits into the SDG framework is imperative to see its connections to all the goals. It is also sensitive enough, when interrupted at any given point, to trigger a chain of reactions involving a broad spectrum of consequences to the biodiversity, environment, and the human society.
\end{abstract}

Keywords- SDG, biodiversity, livelihood, Coral Triangle Initiative, marine resource heritage, community wellbeing, marine protected areas

\section{INTRODUCTION}

People have long wondered how the amazing diversity of life on Earth came to be. The diversity has developed through biological evolution and is affected by interactions among species and by the environment. As the human population increases, human needs and desires come into increasing conflict with habitats and populations of endangered species. Apart from our very own lives and the lives of other people may they be far or near, every action we take will affect biodiversity. Edward O. Wilson published his seminal text on "The Crisis of Biological Diversity" in 1985 and got the world alerted to the threat posed by biodiversity loss [6]. It was then the nation was shot with questions and worries concerning biodiversity - what the crisis is all about, how important it is, or whether we can survive with less biodiversity, whether we are living sustainably enough, what conservation actions or efforts to be taken and the success thus far, and so forth.

Generally, biodiversity is understood as the degree of variation of life forms within a given species, ecosystem, biome, or an entire planet. It is a measure of the health of ecosystems and is in part a function of climate. The
International Union for the Conservation of Nature and Natural Resources (IUCN) [1] defines biodiversity as:

"the variability among living organisms from all sources including terrestrial, marine and other aquatic ecosystems, and the ecological complexes of which they are part; this includes diversity within species, between species, and of ecosystems."

Biologists most often define biodiversity as:

"the totality of genes, species, and ecosystems of a region."

An advantage of these two definitions is that it seems to describe most circumstances and presents a unified view of the traditional three levels at which biological variety has been identified, which are:

i. Species diversity, which refers to the effective number of different species that are represented in a collection of individuals. This level of diversity consists of two components, species richness (a simple count of species) and species evenness (quantifies how equal the abundances of the species are) that sustains ecosystem equilibriums.

ii. Genetic diversity that refers to the total number of genetic characteristics in the genetic makeup or 'genetic pool' of the population of a species. This level of diversity serves as a way for populations to adapt to changing environments 
through the possessions of variations in alleles that are suited for the environment; and

iii. Ecosystem diversity which refers to the diversity of a place at the level of ecosystems. It can also refer to the variety of ecosystems present in a biosphere, the variety of species and ecological processes that occur in different physical settings. Its robust performances are crucial for the mix of life's essentials.

The United Nations designated 2011-2020 as the United Nations Decade on Biodiversity (Resolution 65/161) which serves to support and promote implementation of the objectives of the Strategic Plan for Biodiversity and the Aichi Biodiversity Targets, with the goal of significantly reducing biodiversity loss. Throughout the UN Decade on Biodiversity, governments are encouraged to develop, implement, and communicate the results of national strategies for implementation of the Strategic Plan for Biodiversity. It also seeks to promote the involvement of a variety of national and intergovernmental actors and other stakeholders in the goal of mainstreaming biodiversity into broader development planning and economic activities. The aim will be to place special focus on supporting actions that address the underlying causes of biodiversity loss, including production and consumption patterns [2], [3].

With the dwindling size of high biological diversity marine areas, the need to identify, manage and conserve these areas and finding new habitats for the same purpose is imperative for sustainability of natural marine resources. Given the present circumstance where the global reefs are now at risk [4] particularly in regions with increasing turbid waters, every opportunity to salvage even the tiniest habitat is crucial to revive and to increase the chance to successfully sustain our depleting marine resource heritage which is a fundamental link between our society, economy, and space. It contributes to the model of sustainability where community's wellbeing and livelihood depend on.

\section{Why is biodiversity important?}

Discussions of the value of biodiversity are complicated by the fact that people mean various things when they talk about conservation of diversity. If anyone asks this question, one of the answers is because it represents the almost infinite variety of plant and animal life, and the variety of Earth's ecosystem types that support life as we know it. It enables humans to survive in what would be otherwise some very adverse conditions. People need nature to thrive and our most basic needs and basic conditions are derived from the natural world - to be specific, we need and rely on biodiversity.

Biodiversity too is nature's way of strategic defense. Examples of this defense are the mangroves (e.g., a natural sedimentation trap, fish breeding and hiding ground and shore protector of storm and flood surges), the coral reefs (e.g., high productivity zone, fish breeding ground and shore wave breaker zone), and diversity in genetic pools (disease resistance and immunity) (Fig. 1). Thus, based on major roles it plays, the importance of biodiversity can be grouped into four categories: ecological, economical, services and cultural.

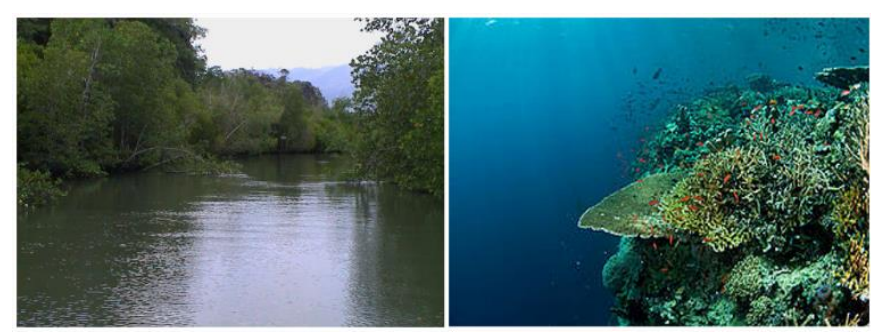

Fig. 1. (a) Mangrove in Pulau Langkawi, Malaysia (Photo: Anisah Lee Abdullah/USM); (b) Reef in Pulau Sipadan, Malaysia (Photo: Jürgen Freund / WWF-Aus)

\section{Threats to Biodiversity}

According to IUCN [5] there are five main threats to our global biodiversity: (1) Habitat loss and degradation, (2) Introductions of Invasive Alien Species, (3) Over-exploitation of natural resources, (4) Pollution and diseases, and (5) Human-induced climate change. E. O. Wilson [6] categorizes the main threats or causes of species extinction in order of magnitude of impact on biodiversity in the acronym HIPPO: Habitat destruction, Invasive species, Pollution, human overPopulation, Overharvesting by hunting and fishing. These threats, if not mitigated, will result in shrinking our biodiversity, which in turn will cause significant human problems: economic cost of lost biodiversity, reduced food security, increased contact with disease, more unpredictable weather, loss of livelihoods and losing sight of nature (Fig. 2) [7]. Other than natural causes and processes, most human activities by and large will ultimately impact on the human themselves. If we examine in detail all the threats to biodiversity listed in various reliable sources, we will find that the humans are themselves the source of it all. The question now lies in how we can intensify our efforts to make people aware of the crucial importance of biodiversity and take necessary actions as we are approaching the 'tipping point' [6], [7].

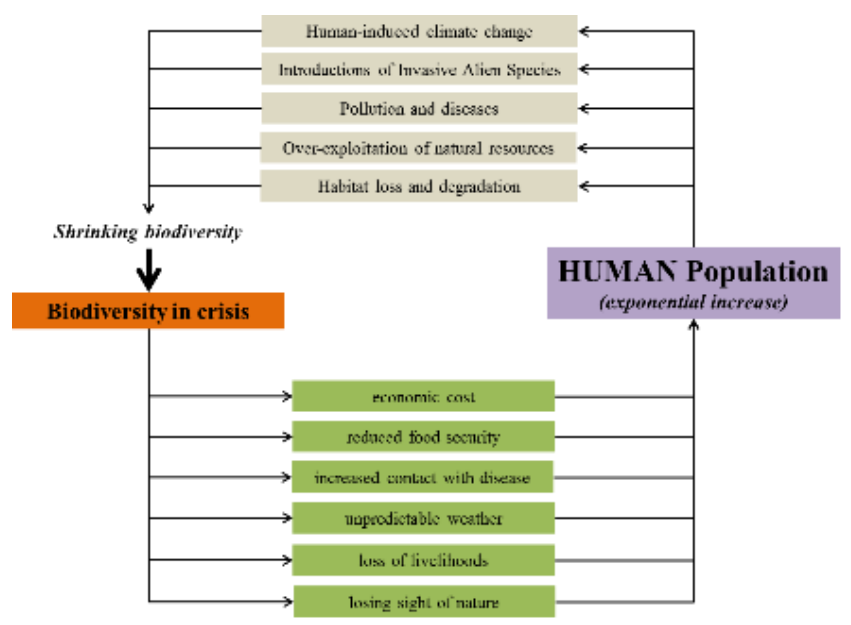

Fig. 2. Cause and Effect of Shrinking Biodiversity (Source: Anisah Lee Abdullah, 2017)

The 2005 Millennium Ecosystem Assessment [8] reported on 'Biodiversity and Human Well-being' illustrating the relationship between biodiversity, ecosystem services, human well-being, and poverty. The illustration shows areas where 
conservation strategies, planning, and intervention can alter the drivers of change from local, regional, to global scales. From 1950 to 2011, world population increased from 2.5 billion to 7 billion and is forecast to reach a plateau of more than 9 billion during the 21st century. Based on information from World Population Data Sheet of 2012 [20], world population grew to 7.06 billion in mid-2012 after having passed the 7 billion mark in 2011 and developing countries accounted for $97 \%$ of this growth. This coupled with the fact that most developing countries are in Asia which is also mostly tropical and subtropical regions where biodiversity is the highest, the massive growth in the human population through the $20^{\text {th }}$ century will have more impact on biodiversity than any other single factor.

\section{COASTAL AND MARINE BIODIVERSITY}

To ensure our concern on biodiversity is properly addressed, it would be natural to humans to logically divide the vast area of our Earth into zones or categories of ecosystems accordingly in order to strategically plan, implement, manage, monitor and evaluate or assess our natural resource, the biological diversity. Different management strategies will be required for different ecosystems which takes into consideration other backgrounds of the region such as the social, cultural, and economic dependence.

The coastal and marine ecosystem is often divided into different categories of ecosystem depending on its purpose, for instance, Exclusive Economic Zone (EEZ), International Hydrographic organization (IHO), Large Marine Ecosystem (LME) and Marine Ecoregion (MEOW). LMEs have been developed by the US National Oceanic and Atmospheric Administration (NOAA) to identify areas of the oceans for conservation purposes. The objective is to use the LME concept as a tool for enabling ecosystem-based management to provide a collaborative approach to management of resources within ecologically bounded transnational areas. LME-based conservation is based on recognition that the world's coastal ocean waters are degraded by unsustainable fishing practices, habitat degradation, eutrophication, toxic pollution, aerosol contamination, and emerging diseases, and that positive actions to mitigate these threats require coordinated actions by governments and civil society to recover depleted fish populations, restore degraded habitats and reduce coastal pollution, hence leading to conservation of biodiversity.

Although the LMEs cover only the continental margins and not the deep oceans and oceanic islands, the 64 LMEs produce 95\% of the world's annual marine fishery biomass yields (Fig. 3) [9]. These LMEs happened to be areas with much, much higher productivities. Concurrently, most of the global ocean pollution, overexploitation, and coastal habitat alteration also occur within their waters. Peninsular Malaysia is surrounded by the Straits of Malacca on the west and South China Sea on the east, while the Borneo island (which locate Sabah and Sarawak) is surrounded by the South China Sea on the west of the island and the Sulu-Celebes Sea on the east.

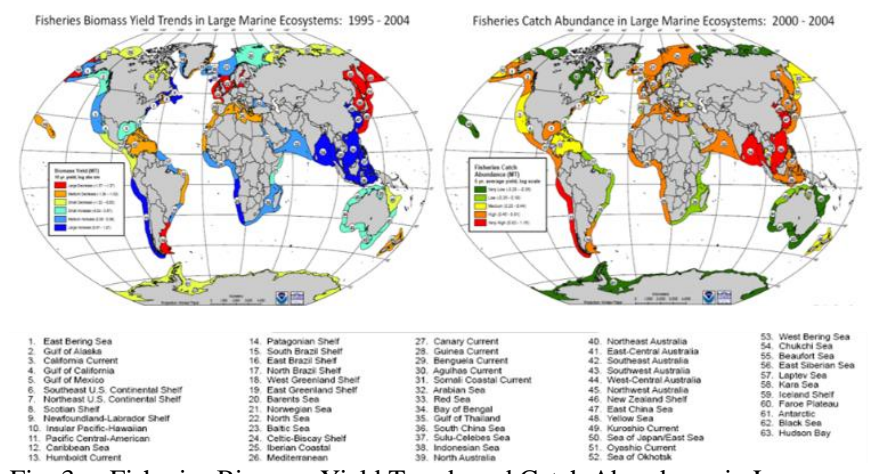

Fig. 3. Fisheries Biomass Yield Trends and Catch Abundance in Large Marine Ecosystems. (Source: NOAA, 2012)

Categories of coverage zones for Malaysian waters will differ depending on the types of ecosystem. For instance, under IHO, Malaysian waters will fall within the categories of Malacca Strait, South China Sea, and Singapore Strait. Under MEOW, Malaysian waters will cover Malacca Strait and Sunda Shelf/Java Sea; while under LME, Malaysian waters will include Bay of Bengal, Sunda Shelf/Java Sea, Gulf of Thailand, and the Sulu-Celebes Sea [10].

Reports from Ocean Biogeographic Information System (OBIS) on "The State of Knowledge on Marine Biodiversity" in 2012 [11] during the Oceans side event at Rio+20 (UN Conference on Sustainable Development), Patricia Miloslavich, stated that there is a record of 250,000 known marine species. This number only represented about $10 \%$ of estimated real biodiversity because the vast majority of earth's ocean is yet to be explored (about 95\%) and new species are being continuously discovered even in explored areas. There is an estimate of at least 1 million marine species existing on earth excluding the microbes. The marine biodiversity of crustacean, mollusks and pisces represented almost $50 \%$ of the total known records where a substantial number of species in these groups are of commercial importance. The microbial diversity tops the number of species orders of magnitude. For instance, in a liter of seawater alone may contain more than 38,000 different kinds of microbes. These microbes constitute $90 \%$ of ocean biomass and are essential to maintaining Earth's habitability and functioning. The diversity of microbes is responsible for more than $95 \%$ of respiration in the oceans, but also influence climate, recycle nutrients, decompose pollutants, and constitute the base of the food web that supports all life on the ocean.

A global analysis of the distribution of coastal species shows highest species richness in the tropics, and marine hot spots appear around the Philippines, Japan, China, Indonesia, Australia, India, Sri Lanka, South Africa, the Caribbean and the southeastern United States. On the other hand, oceanic species richness peaks in temperate latitudes. An analysis of species richness in more than 25 regions of the world, confirms high marine biodiversity in Japan, Australia, and the China Seas, and shows high endemicity (species confined to a particular region) or uniqueness, between $22 \%$ and up to $48 \%$, in South America, Australia, New Zealand, South Africa and Antarctica, all within the southern hemisphere of the Earth. 
The coastal and marine environment is rich in its diversity of life. Within this environment, the coral reefs have the highest productivity and are considered the rainforests of the sea. With it harbours a broad range of biological diversity ranging from microorganisms to the largest mammal on earth. Veron [12] stated that Southeast Asian waters harbour the highest diversity of coral genera ( $>70$ genera) and is coined as the 'Coral Triangle'. Veron and Smith [13] later charted from 200 to more than 500 species of corals that can be found within the Coral Triangle of Southeast Asia (Fig. 4). Considered as the world's marine life hotspot, the Coral Triangle is in the waters off the coasts of Indonesia, Malaysia, Papua New Guinea, the Philippines, Solomon Islands and Timor-Leste. This hotspot is known to contain the highest diversities of iridescent corals, fish, crustaceans, mollusks, and marine plant species on Earth [14].

A global, map-based analysis of threats to the world's coral reefs called Reefs at Risk Revisited, a research spearheaded by the World Resources Institute (WRI) in a broad collaboration with leading conservation organizations and research institutes, reported detailed examination of human pressures on coral reefs, implications for reef condition, and projections of associated impacts in coastal communities in 2011 [4]. In this report, Southeast Asia, having the most extensive and diverse coral reefs in the world makes up $28 \%$ of the global total reef area i.e. almost $70,000 \mathrm{~km}^{2}$. These reefs concentrated around insular Southeast Asia, where fringing reefs predominate and supplemented by barrier reefs such as the extensive Palawan Barrier Reef in the Philippines.

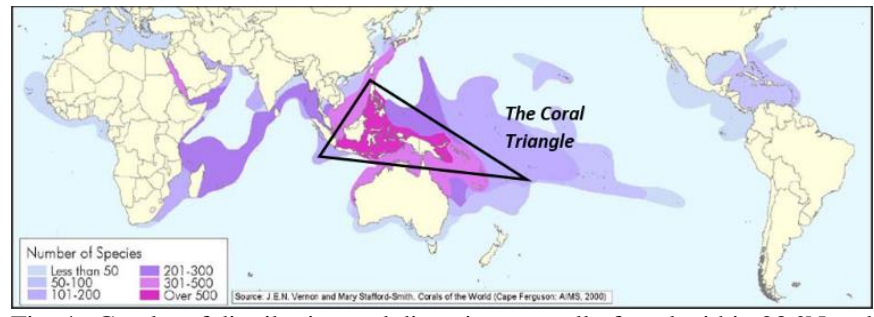

Fig. 4. Coral reef distribution and diversity generally found within $23^{\circ} \mathrm{N}$ and $23^{\circ} \mathrm{S}$ and the boundary of Coral Triangle (Source: Veron \& Smith, 2000).

One-eighth of the world's population-roughly 850 million people-live within $100 \mathrm{~km}$ of a coral reef and are likely to derive some benefits from the ecosystem services that coral reefs provide. More than 275 million people live very close to reefs (less than $10 \mathrm{~km}$ from the coast and within 30 $\mathrm{km}$ of reefs) [4]. Many of these people live in developing countries and island nations where dependence on coral reefs for food and livelihoods is high. In Southeast Asia alone, more than 138 million people live on the coast within $30 \mathrm{~km}$ of a reef which is more than every other region combined. Fish, including reef fish, form a major part of the diet even in urban populations. Fish and seafood provide an average of 36 percent of dietary animal protein across this region [4].

Reefs in this region are the most threatened in the world 95\% are at risk from local threats with almost half in the high and very high threat levels. There are four major local threats identified by WRI in 2011 based on developed integrated threat indices - coastal development, marine-based pollution, and damage, overfishing and destructive fishing, and watershed-based pollution [4]. In its report, WRI stated that the largest proportion of threatened reefs are in Southeast Asia, where nearly $20 \%$ of the reefs are threatened by coastal development, and $45 \%$ threatened by watershed-based pollution. According to the report, unsustainable fishing is the most pervasive of all local threats to coral reefs in Southeast Asia, with almost $95 \%$ of reefs affected. Densely populated coastlines, shallow and easily accessible fishing grounds, as well as the highest global occurrences of blast and poison fishing contribute to this threat in the region.

Coral reefs are harbingers of change. The degradation of coral reefs is a clear sign that our dangerous overreliance on its natural resources is already changing Earth's climate. If we continue down this path, all corals will likely be threatened by mid-century, with $75 \%$ facing high to critical threat levels. In acknowledging and recognition the importance of the world's marine life hotspot along with the increasing threats and possible environmental, ecological, social and economic consequences, a Coral Triangle Initiative on Coral Reefs, Fisheries and Food Security (CTI-CFF) was formed in 2007 by six Coral Triangle governments (Indonesia, Malaysia, the Philippines, Papua New Guinea, the Solomon Islands and Timor-Leste) also known as CT6 (Fig. 5). The CT6 has agreed to support people-centered biodiversity conservation, sustainable development, poverty reduction and equitable benefit sharing. The CTI-CFF seeks to address both poverty reduction through economic development, food security, sustainable livelihoods for coastal communities and biodiversity conservation through the protection of species, habitats, and ecosystems [16]. The Coral Triangle Boundary is further subdivided into smaller zones, Coral Ecoregions (Fig. 6).

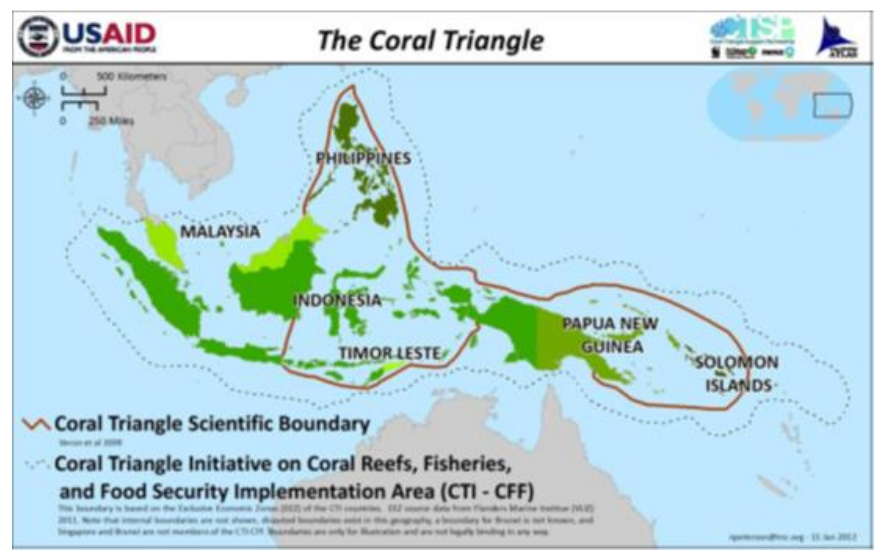

Fig. 5. The Coral Triangle Initiative Boundary. (Source: CTI, 2012)

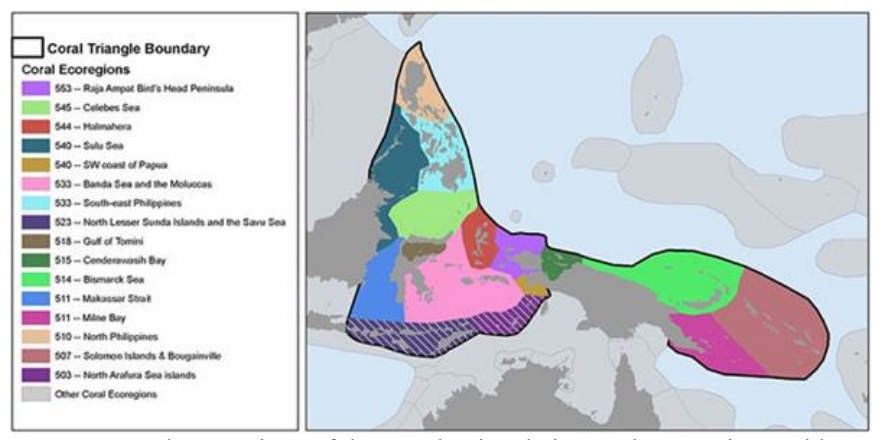

Fig. 6. Coral Ecoregions of the Coral Triangle in Southeast Asia, world's marine life hotspot. (Source: CTI, 2012) 
Spanning 648 million hectares, the ecosystems of the Coral Triangle support the livelihoods of over 340 million people spread across the CT6 [16]. This abundant marine ecosystem is now at risk where unsustainable fishing, rapid population growth and the effects of climate change are damaging the environment and threatening the food security of those depending on the valuable natural resources within the region. Around $80 \%$ of marine species in the Coral Triangle can be found in Malaysia's waters but rapid coastal development coupled with its fast-growing economy have taken their toll on its resources. In the Sulu Sea region, bordering East Malaysia, there are at least 1200 fish species. Water quality is declining as an after effect of unplanned coastal development while trawling near coral reefs and sewage discharge continuously threatens its marine habitats. Fish stocks are depleting due to overfishing and, illegal and destructive fishing methods. Fisheries play an important role in Malaysia's culture and economy. Malaysia is a nation with more sea than land and its exclusive economic zone is 1.5 times larger than its land area. In Malaysia, $98 \%$ of its people live within $100 \mathrm{~km}$ of its coastline and fisheries provided $60 \%$ of the population's protein [4], [16]. Fisheries are vital for food security and livelihoods in poor coastal communities of this region. Most importantly, these fishery resources are dependent on its habitat, its feeding, breeding, and hiding grounds - the coral reefs and the mangroves [16].

\section{The role of Marine Protected Areas (MPAs) or Marine Reserves}

According to Kelleher [15], a marine protected area (MPA) is defined as,

"any area of intertidal or subtidal terrain together with its overlying water and associated flora, fauna, historical and cultural features, which has been reserved by law or other effective means to protect part or all of the enclosed environment."

It is unquestionable that MPAs play a critical role in protecting marine biodiversity, ecosystem function and sustaining healthy coastal communities. Depending on the degree of human dependence (e.g., social, and economic) on the reefs, gazetted MPAs will aid in biodiversity conservation at species, genetic and ecosystem levels which will promote and regulate sustainable grounds for fisheries such as breeding and hiding grounds to ensure fish stocking and hence food security if properly managed, otherwise there will be reef loss. However, there are challenges globally faced by MPAs. For instance, the possibility of insufficient financial resources and technical resources, reliable trained staff, insufficient data for decision making and management, public awareness and implementation force will affect the overall effectiveness to achieve MPAs objectives and goals. To provide and to demonstrate long term positive impacts on biodiversity and the human communities depending on these resources, performance evaluation will have a critical role as this should ultimately lead to improved project planning, accountability and adaptive management, including the ability to change management as needed due to unanticipated impacts and/or changes outside the scope of the MPA.
WRI [4] assessed social and economic vulnerability of countries and territories to reef loss based on exposure to reef threats, reef-dependence, and adaptive capacity on eighty-one countries, 21 island territories, and six sub-national regions (Florida, Hawaii, Hong Kong SAR, Peninsular Malaysia, Sabah, and Sarawak) categorizing them according to quartiles (low, medium, high, and very high) [4]. The marine waters of Malaysia fell within the medium to very high social and economic dependence on coral reefs (Fig. 7) and therefore at the stage of medium to very high vulnerability to reef loss (Fig. 8). Between 1998 and 2007, Malaysian waters undergo changes in local threat where there are areas with almost no change in threat level (east coast of Peninsular Malaysia) and areas with an increase in threat levels in South China Sea (Fig. 9). WRI [4] then classified reefs of the world based on integrated local threat index of threats from local activities and Malaysian reefs are in the medium to very high threat level (Fig. 10). With this information, the reefs around Malaysia will have low capacity to adaptation to reef degradation and loss (Fig. 11).

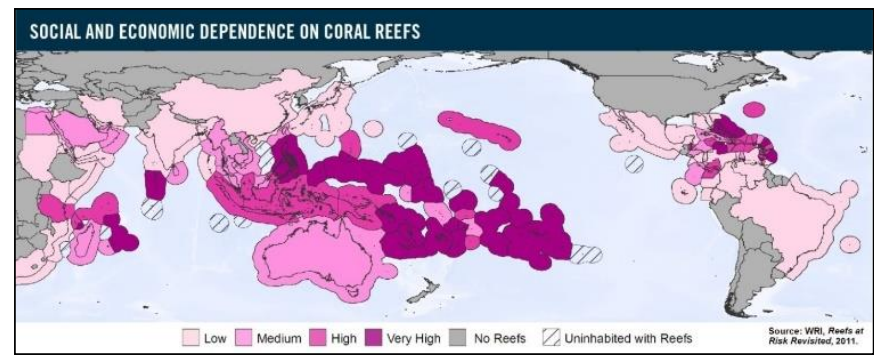

Fig. 7. Social and economic dependence on coral reefs. (Source: WRI, 2011)

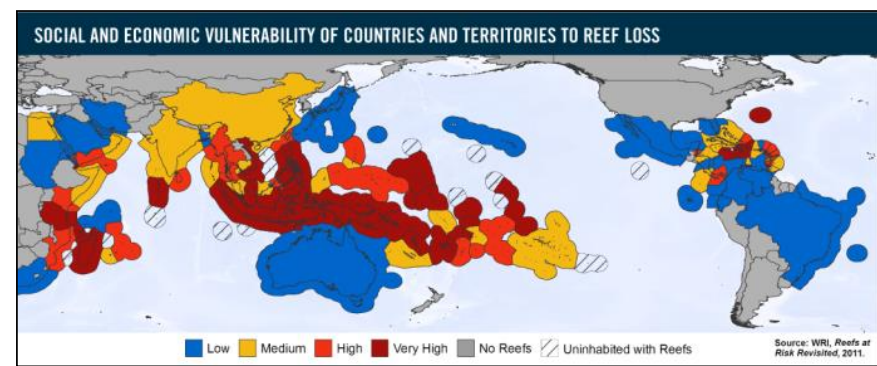

Fig. 8. Social and economic vulnerability of countries and territories to reef loss. (Source: WRI, 2011)

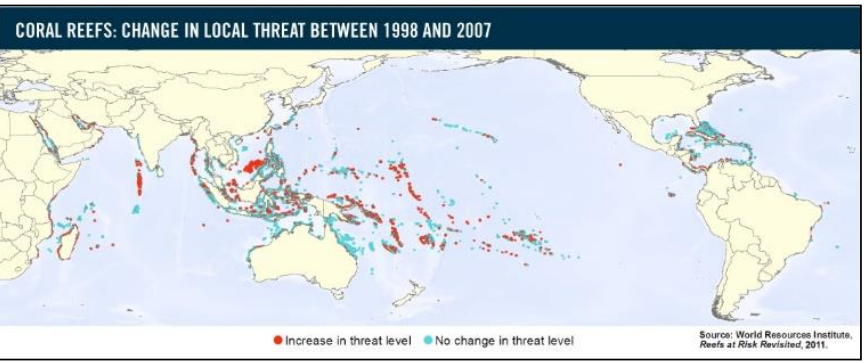

Fig. 9. Coral reefs: changes in local threat between 1998 and 2007. (Source: WRI, 2011) 


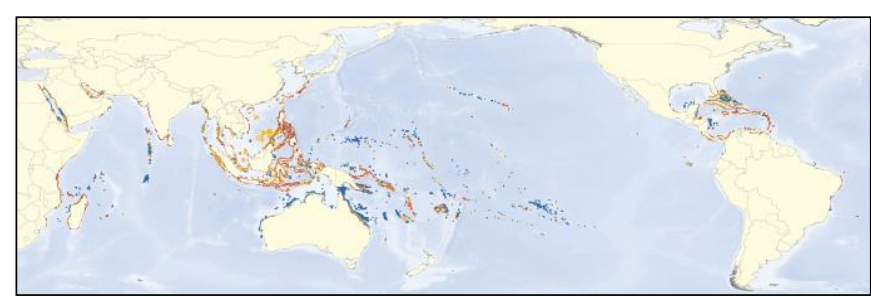

Fig. 10. Coral Reefs of the World Classified by Threat from Local Activities, according to the Reefs at Risk integrated local threat index. (Source: WRI, 2011)

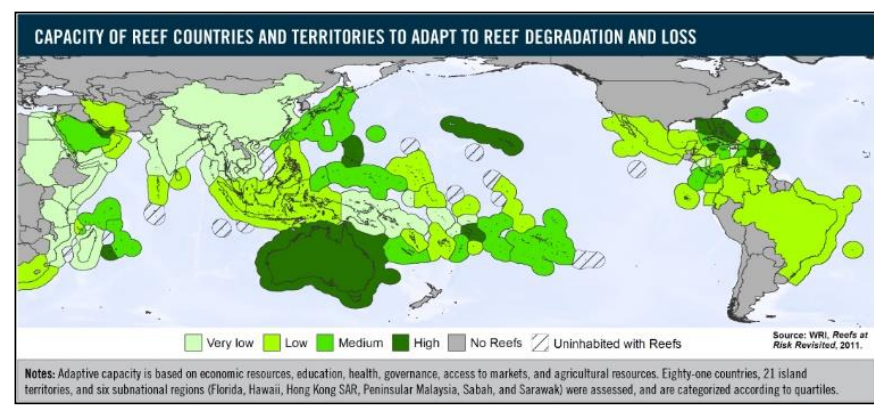

Fig. 11. Capacity of reef countries and territories to adapt to reef degradation and loss. (Source: WRI, 2011)

Within the Southeast Asia region, there are nearly 600 Marine Protected Areas (MPAs) covering 17 percent of the region's reefs. However, only $3 \%$ of the region's marine protected reefs are rated based on an effectiveness level using 3-point score as effectively managed. Malaysian MPAs, the larger and known ones are unfortunately not effectively managed, whilst the smaller ones are unrated (Fig. 12). Malaysia has 17 MPAs and since the establishment of CTICFF in 2007 and being one of the members of the CT6, with the support of WWF-Malaysia and CTSP, the government is establishing the Tun Mustapha Park, which will be one of the largest Marine Protected Areas in Southeast Asia under CTI [16]. This MPA spans one million hectares. By supporting work that delivers the CTI-CFF Malaysian National Plan of Action, CTSP helps the government address the greatest threats and challenges to Malaysia's coastal resources. WWFMalaysia works with the government to introduce more sustainable fishing methods on local and national levels. An essential part of this process involves fishers and local merchants, as their ideas will help develop policies that address a realistic and unified vision for Malaysia's marine resources [16].

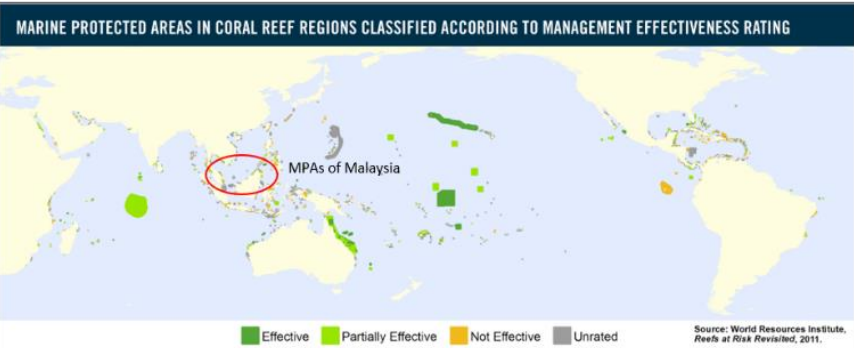

Fig. 12. Marine Protected Areas in Coral Reef Regions classified according to Management Effectiveness rating. (Source: WRI, 2011)

There are efforts to protect, conserve and rehabilitate our marine reserves at different scales. However, the success of it all depends on numerous drivers along with the support and integration of various factors. These drivers and factors encompass both measurable and non-measurable values. For instance, an increase in coral growth and biodiversity resulting in a positive outcome of combined efforts is measurable, but public awareness levels and the contribution of these awareness where conservation is concerned is not measurable. According to Roberts [17], reserves will work only if we have evidence that reserves all over the world show dramatic increases in spawning stocks usually by at least 2-3 times within 5-10 years. Long-term studies in New Zealand, Philippines, Florida, and many other countries show strong responses to reserve protection.

Roberts [17] mentioned that fishes in reserves for example do live longer, grow larger and produce more eggs. However, public awareness alone without implementation of the public knowledge into practices within the reserves will not make conservation happen. Therefore, having MPAs or marine reserves will not be fruitful, in fact may be more devastating than otherwise, unless full measures of other aspects of rehabilitation and conservation are supported and in tight reign implementation. Stringent measures, coupled with the driving force of current worrying Living Planet Index and Ecological Footprint, should be in the horizon for a local, regional, and global success stories [4].

\section{Concern and Hope for Marine Diversity: Degradation and Rehabilitation of Species}

Genetic diversity and biodiversity are dependent upon each other very delicately in that diversity within a species is necessary to maintain diversity among the species, and vice versa [18]. According to the lead researcher in the study, Dr. Richard Lankau, "If any one type is removed from the system, the cycle can break down, and the community becomes dominated by a single species." Genetic diversity has central role in species survival and adaptability. Species with little genetic variation are vulnerable to certain types of diseases and are at very high risk of facing extinction. If biodiversity shrinks and species degrade, intensive rehabilitation should be implemented. Seagrass and wetland habitat, one of the breeding grounds of an abundant of marine organisms, have been eliminated by human activities by as much as $65 \%$ [16].

In past decades, disposal of waste and litter had the most significant anthropogenic impact on the marine environment. Presently, the biggest impact comes from exploitation (e.g. fisheries, hydrocarbon, and mineral resources). In the future, climate change is likely to bring more global effects, including warming, ocean acidification, and expansion of hypoxic and oxygen minimum zones. Climate change predictions for marine life investigation showed that coral reefs are at high risk of extinction due to greenhouse gas emissions and the effects of ocean acidification. The good news is that recovery is possible if action is taken. Where conservation efforts were implemented, populations of some marine species recovered. In contrast to rapid depletion, however, recovery tends to be slowed, particularly the slow growing corals.

In the coastal environment, researchers documented that the fastest path to recovery was achieved by mitigating the cumulative impacts of human activities. Seventy-eight percent of documented recoveries occurred, for example, when at least 
two human activities, such as resource exploitation, habitat destruction, and pollution, were reduced.

\section{Sustainable management aspects}

Although the ocean provides livelihoods and a place to live, overexploitation will lead to disastrous global predicament. Since the first World Summit in 1992, we have gaps still to be filled. For instance, the commitment to maintain or restore depleted fish stocks to levels that can produce their maximum sustainable yield no later than 2015 has not been implemented, and the JPOI (Johannesburg Plan of Implementation) commitment to support the sustainable development of aquaculture is not yet in place globally; very limited progress towards implementation of an ecosystem approach has been made despite the hope for widespread implementation by 2010, marine pollution from land based resources remains a serious problem, particularly in nations that lack either technical capacity, or physical space to deal with the issue as reflected (for example) in the continued rapid growth of hypoxia in the coastal zones of many countries. Regarding biodiversity and MPAs, commitments from the JPOI call for the reduction of biodiversity loss by 2010, the establishment of representative networks of MPAs by 2012, and reversing the trend in natural resource degradation have all fallen far short [19].

All of these stemmed from barriers to implementation due to alternative political priorities, insufficient institutional capacity or inappropriate institutions, market distortions, incomplete science, lack of financing, and/ or willingness of participants. Much relates to the fundamental perception that full implementation would require a trade-off among the different pillars of sustainability. Therefore, the changes that will be required to transition to a Blue-Green Economy will be a mix of physical, behavioural, and institutional. Based on Rio+20 Blueprint for Ocean sustainability [19], the focal actions are:

i. reduce stressors and maintain or restore the structure and function of marine ecosystems for equitable and sustainable use of marine resources and ecosystems,

ii. support the Green Economy concept leading to alleviation of poverty and promotion of sustainable ocean sectors and livelihoods including actions to improve implementation at local levels through participatory processes,

iii. actions resulting in Policy, Legal and Institutional Reforms for effective Ocean Governance, including in the High Seas, and strengthening the institutional framework, mandate, and coordination of UN bodies with marine competencies, and

iv. actions supporting marine research, monitoring and evaluation, technology, and capacity transfer as a mean for improving knowledge, addressing emerging issues, developing capacities in support of sustainable use of the ocean.

\section{Knowledge Gaps}

There is a need at all levels to acknowledge that, major gaps exist in our knowledge of coastal and marine biodiversity and its sustainability. This verifiable truth should serve as the basic driving force to address and fill our deficiency to logically plan and implement sustainable management strategies catered for different marine ecosystems. Our deficiency lies within the 'evolving' known, the unknown, and unknowable marine biodiversity.

Malaysia sits on the Sunda continental shelf rich in marine biodiversity or is the hotspot areas, coupled with low to high human impacts resulting an area with high complexity where charting the history of marine species, inventorying and monitoring existing diversity is concerned. Although many known marine species have been recorded, the unknown stays a big scientific challenge whilst the unknowable remains untold. Based on gathered global census, information to the Sunda continental shelf waters still point to blanks or at very minimal availability which poses many great challenges related to marine biodiversity knowledge and understanding that remain.

In addressing these challenges, a new initiative, Life in a Changing Ocean, was presented and discussed in September 2011, where the goal is to advance discovery and expand marine biodiversity knowledge to support healthy and sustainable ecosystems through an integrated global view of marine life that will fill knowledge gaps and answer questions needed to effectively manage and sustain ocean ecosystems. Hence, as a result of the consultation, the main scientific challenges related to marine biodiversity that can be integrated across three interrelated and interconnected themes are: (1) Biodiversity Discovery in Time and Space, (2) Biodiversity and Ecosystem Services and Functions, and (3) Biodiversity and Human Exploitation [10]. Improved knowledge of biodiversity is pivotal in the integration of these themes for Sustainable Use and Conservation.

\section{(i) Innovative tools, technologies, and methods for ecosystem management}

Governments recognize the need to have integrated approaches to protect and improve our environment from deleterious human activities [21]. Demands of different ocean uses are imperative and require reconciliation. Through several global meetings like the 2002 World Summit on Sustainable Development's International Plan for Implementation, 2010 Convention on Biological Diversity, and the recent Earth Summit 2012, countries and international bodies have strengthened their commitments to integrated management by adopting marine spatial planning and ecosystem approaches to management [2]. The realization of the pressing need to fall into action has prompted the setting up of various initiatives such as the CTI-CFF for the CT6 in 2007 [16]. National plans for countries are drawn to include preservation of the structure and natural resilience of an ecosystem requiring greater scientific information gathering and sharing across all sectors involving innovative tools, technologies, and international standardized methods. The Census of Marine Life (COML) [10], for instance, helps to overcome global data constraints by consolidating existing information, developing tools for rapid collection of new and detailed data, and piloting ecosystem-based approaches to management. 


\section{(ii) Marine Protection Decisions at Ecosystem Level}

Many marine ecosystems are connected by ocean currents and shared stocks (travelling marine species), which makes trans-boundary issues vital to decision makers in conservation, industry, and government. The COML [10] for example, uses advanced tagging technologies on iconic trans-boundary fished species. Data documented reveal previously unknown information about species habitat such as natal homing of the tuna, or ecosystem connectivity through the long-distance movement of marine species, congregation of marine species, pointing to hotspots and breeding ground corridors. One such example is the tracking of sea turtles. Endangered Leatherback Turtle, Dermochelys coriacea, one of the five species inhabiting Malaysian waters, had been found to commute between Malaysia's coastal marine region of Borneo to Mexico (Fig. 13) [10]. These records are de rigueur in rehabilitation and conservation efforts for sustainable marine biodiversity and in assisting the CBD in defining potential ecologically or biologically significant areas (EBSAs) in areas beyond national jurisdiction. Such documentation will also facilitate efforts of CTI-CFF [16].

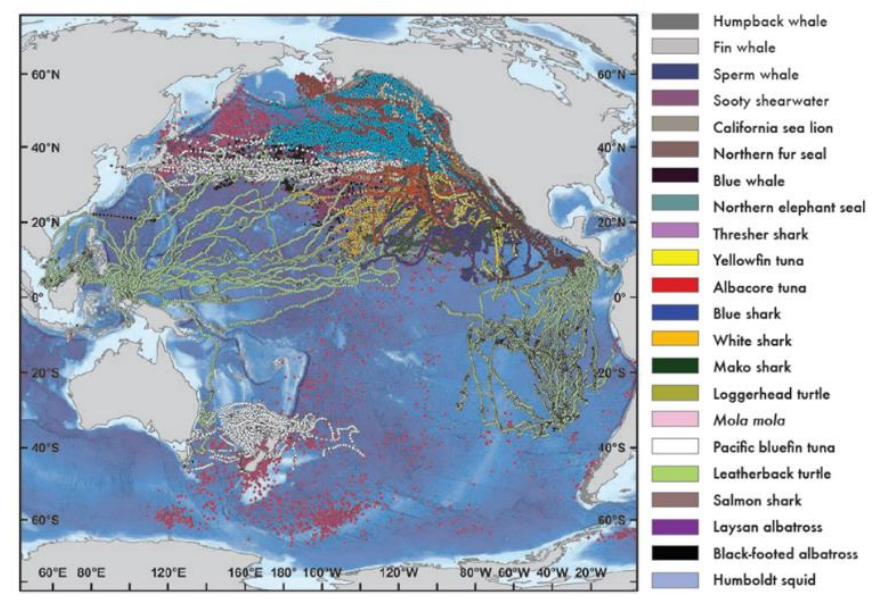

Fig. 13. Census of tracked marine species. (Source: COML, 2012)

\section{(iii) Capacity Building}

Worldwide, major gaps exist in sampling effort and taxonomic expertise. In this regard, knowledge of biodiversity is related to the availability of local and regional species identification guides [12]. Therefore, capacity building in this aspect is fundamental to facilitate the discovery of new species and help to identify and understand species of economic and ecological importance. Hence, there is an essential need for cooperation built based on human, technological, and institutional capacity at the global, regional, national, institutional, and individual levels. Research targets in countries can be identified, enhancing local support for marine biodiversity projects, and the creation of educational opportunities to contribute to the generation of marine life and biodiversity knowledge for decades to come. Shared technologies and approaches across countries will result in increasing institutional and personal capacity, shared data standards, and complementary sampling and data collection for regional and global analysis. In the coastal (tidal and intertidal) zone, such as the near shore project of NaGISA can serve as an ambassador project where international cooperation and capacity building can be encouraged for inventorying and monitoring coastal biodiversity. This will link common global goals with local interests in building capacity and awareness.

\section{(iv) Partnerships and Complementary Relationships to maximize knowledge enrichment and sharing.}

In knowledge enrichment and sharing, naturally the main partnerships are among scientists and their institutions. However, as potential uses of the results emerged, complimentary relationships with various other key partners such as the IUCN, the CBD and the UN's Food and Agriculture Organization (FAO) need to be built in order to maximize the utility of findings for the purpose of management and policy applications. At the level of public, partnerships with National Geographic for videos, documentaries, and maps, along with other media sites will help build public awareness. Local publics can be informed through museum and aquarium displays, school visits, art and other outreach activities via government agencies, industries, conservationists, scientists, and educators.

Based on the aims, goals, action plans, output, knowledge gaps and gathered reports, it is clear the role of Coral Triangle plays and fits into the SDG framework. How CTI connects all the 17 SDGs are provided in Fig. 14. It is evident how an interruption or provocation to any point within the framework will trigger a chain of reactions and possibly disorder involving a broad spectrum of consequences to the biodiversity, environment, and the human society.

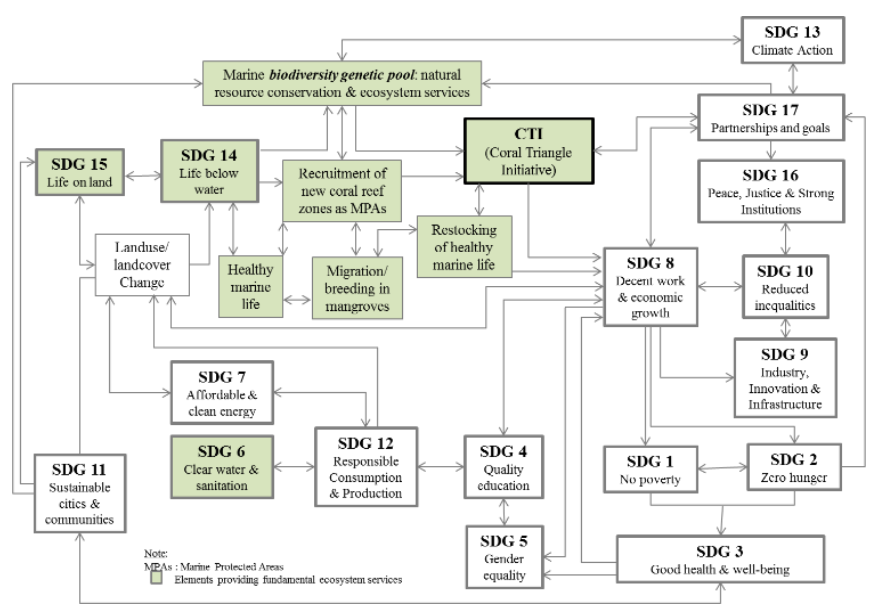

Fig. 14. Role and contributions of Coral Triangle Initiatives (CTI) towards United Nation's Sustainable Development Goals (SDGs).

\section{CONCLUSIONS}

What we do on land will affect the coastal and marine environment and what happens to these environments will affect us no matter where we live on the face of earth. We need to recognize that no one else is responsible for our lives and wellbeing but ourselves. Biodiversity, defined by its genetic, species and ecosystem diversities, need to be conserved for the present and future. Genetic diversity is important for adaptations, species diversity sustains ecosystem equilibriums, and the robust performance of diverse ecosystems is crucial for the mix of life's essentials. Its value extends far beyond 
fisheries providing natural products and services which life on earth depends on. These resources provide essential economic, environmental, aesthetic, and cultural benefits to humanity. With its diverse habitats and breeding grounds, the coastal and marine environment offers valuable protein source for at least 3 billion people and moderates global climate change. The world's oceans host 32 of the 34 known phyla on Earth and contain between 500,000 and 10 million marine species. Hence, the genetic resources in the coastal and marine region are of actual and potential interest for commercial uses.

Damage to the reefs due to multitude long term threats, and with the increasing pressure of human population and accelerated demands for food, products, services, and space from these environments, the health of marine biodiversity is becoming huge environmental issue. Globally, we are now left with a daunting prospect of undoing what we have done. Since the ocean and its biodiversity provide livelihoods and a place to live, they are the major contributors to the global economy and fundamental to global wellbeing; through direct and economic activities, provisions of environmental services, and as home to the majority of the world's population. The key issues affecting ocean and biodiversity sustainability have long been ascertained - unsustainable fishing, climate change and ocean acidification, pollution and waste, loss of habitats and biodiversity, and invasive species. Highlighted in Rio+20 Earth Summit 2012 [19] under the Blue-Green Economy that sustainable ocean and coastal management is highly interconnected of which the coasts and the ocean provide multiple opportunities for addressing poverty, through a range of economic sectors. Therefore, perhaps we should deliberate further into poverty alleviation and augment the state of livelihoods of our coastal communities. Implementation, political and institutional willingness, capacity, and desire to change at all levels of both government and industry are obligatory now more than before. In the opinion of the author, to achieve management effectiveness and hence sustainability of the coastal and marine zone particularly in Malaysia, perhaps impacts of all development across jurisdictional boundary between the land and the sea should first and foremost be considered in great magnitude of significance and earnestness.

\section{REFERENCES}

[1] IUCN, International Union for the Conservation of Nature and Natura Resources (1982). International Year of Biodiversity. Website: http://www.iucn.org

[2] Convention on Biological Diversity (2010). The Strategic Plan for the CBD (press brief).

[3] CBD, Convention on Biological Diversity (2011). UN Decade on Biodiversity website (http://www.cbd.int/2011-2020/).

[4] WRI, World Resource Institute (2011). Reefs at Risk Revisited. Compiled by Lauretta Burke, Katie Reytar, Mark Spalding, and Allison Perry. February 2011. Publ. WRI. 130 pp.

[5] IUCN, International Union for the Conservation of Nature and Natural Resources (2011). The IUCN Red List of Threatened Species ${ }^{\mathrm{TM}}$ Regional Assessment. Publ. IUCN Centre for Mediterranean Cooperation. 61pp.

[6] Wilson, E.O. (1988). Biodiversity. National Academy Press Washington, D.C. 1988. ISBN: 0-309-56736-X, 538 pages

[7] Anisah Lee Abdullah (2017). Chapter 13: Coastal Encroachment, Biodiversity Coastal Encroachment, Biodiversity and Distribution of Natural Coastal and Marine Resources in South Asia. In: Regional Cooperation in South Asia: Socio-economic, Spatial, Ecological and Institutional Aspects. Contemp. South Asian Studies, Sumana
Bandyopadhyay et al. (eds.) (2017). Pp. 225-248. International Springer Publishing AG 2017. ISBN 978-3-319-56746-4

[8] MEA, Millennium Ecosystem Assessment (2005). Ecosystems and Human Well-being: Biodiversity Synthesis. World Resources Institute, Washington, DC.

[9] NOAA, National Oceanographic and Atmospheric Administration (2012). Large Marine Ecosystems of the World. Website: http://www.lme.noaa.gov/index.php?option=com content \&view=artic $\underline{\text { le\&id }=47 \& \text { Itemid }=28}$

[10] COML, Census of Marine Life (2012). Scientific Results to Support the Sustainable Use and Conservation of Marine Life: A Summary of the Census of Marine Life for Decision Makers. 16 pp. Publ. coml.org.

[11] OBIS, Ocean Biogeographic Information System (2012). State of Knowledge on Marine Biodiversity by Patricia Miloslavich at Rio+20. UNESCO-IOC/IODE

[12] Veron, J.E.N. (1993). Corals of Australia and the Indo-Pacific. University of Hawaii Press; 2nd edition (March 1, 1993). ISBN-13: 978-0824815042. $656 \mathrm{pp}$.

[13] Veron, J.E.N. and M. Smith (2000). Corals of the world, Volume 2 Publ. Australian Institute of Marine Science, 2000. 489 pp.

[14] WWF-Australia (2012). https://wwf.panda.org/?205391/gillardgovernment-rio20-oceans-announcement-a-welcome-investment-inprotection-for-coral-triangle-and-pacific

[15] Kelleher, G. (1999). Marine Protected Areas. In: Marine Protected Areas - Why have them? IUCN. 2010. Website: http://www.iucn.org

[16] CTI-CFF (2009). Malaysia: Draft National Plan of Action. October 2009. Publ. Ministry of Science, Technology, and Innovation. 73 pp.

[17] Roberts, C. (2004). The role of marine protected areas in sustaining fisheries.

http://www.un.org/Depts/los/consultative process/documents/6 robert $\underline{\text { s.pdf }}$

[18] NSF, National Science Fund (2007). Genetic Diversity. Website: http://genethics.com/genetic-diversity/

[19] Rio+20 (2012). A Blueprint for Ocean and Coastal Sustainability. UN Conference on Sustainable Development. 2012. 45 pp.

[20] Population Reference Bureau (2012). "World Population Growth, 1950-2050"

[21] UNCHE (1972). Stockholm United Nations Conference on the Human Environment, 1972. 